

\title{
ADSORÇÃO DO AZUL DE METILENO UTILIZANDO CASCA DE ARROZ
}

\author{
J. H. P. SANTOS ${ }^{1}$ e M. B. SILVA ${ }^{2}$
}

${ }^{1}$ Universidade Federal do Triângulo Mineiro, Departamento de Engenharia Química

${ }^{2}$ Universidade Federal do Triângulo Mineiro, Departamento de Engenharia Química E-mail para contato: bacciuftm@gmail.com

\begin{abstract}
RESUMO - Devido ao aumento da produção industrial surgem diversos problemas ambientais, dentre eles a poluição por corantes. $O$ uso da biomassa casca de arroz (CA), material adsorvente, é uma alternativa promissora para o tratamento dos efluentes industriais. Este trabalho avalia a capacidade de adsorção do azul de metileno (AM), usando a CA como adsorvente. O teor de AM foi determinado por espectrofotometria de UV-visivel (664nm). Testes de adsorção foram realizados, sob agitação constante, variando concentração, $\mathrm{pH} e$ quantidade de biomassa. Os resultados mostraram que há potencial de utilização da CA para a remoção do AM em soluções aquosas.
\end{abstract}

\section{INTRODUÇÃO}

$\mathrm{O}$ aumento das atividades industriais tem ocasionado problemas ambientais, como poluição das águas. Efluentes contendo corantes necessitam de alternativas mais inovadoras para remoção dessa poluição (Carvalho et al., 2010). Pesquisas são realizadas para avaliar a eficiência das biomassas para a adsorção de contaminantes distintos (Silva et al., 2014).

A adsorção é um processo de separação sólido-líquido, caracterizado pela transferência de massa, na qual os componentes presentes em baixas concentrações na fase fluida, ou moléculas na fase fluida, são transferidos para a superfície de um sólido, chamado adsorvente. A espécie química retida nos poros da superfície do adsorvente é chamada adsorvato (McCabe et al., 2001). O mecanismo dessas separações é a transferência de massa e o princípio é a afinidade que certos sólidos têm em se concentrar na superfície de determinadas substâncias em solução líquida (Gomide, 1983).

Numa operação de adsorção, medem-se os volumes ou as massas de fluidos por grama de adsorvente sólido, em função da temperatura, à pressão constante. Assim, são obtidas as isotermas de adsorção. Para o estudo da adsorção, os dados de equilíbrio são descritos através de um modelo matemático, apresentados na forma de isotermas de adsorção. As isotermas de adsorção são representadas por equações que relacionam diretamente o volume adsorvido em função da pressão e/ou concentração do adsorvato, frequentemente (McCabe et al.,2001).

O corante azul de metileno (AM) é aplicado na adsorção, pois sua molécula serve como modelo para os demais corantes, já que as bandas de absorção de suas diferentes espécies aparecem em regiões diferentes do espectro com registros conhecidos (Oliveira et al., 2013). O presente trabalho estuda a eficiência da adsorção da CA como adsorvente para remoção do 




AM como adsorvato.

\section{MATERIAIS E MÉTODO}

Salinizou-se a CA com água corrente por 60 minutos, removendo impurezas. Depois a $\mathrm{CA}$ foi seca à temperatura ambiente durante uma semana e na estufa à $70^{\circ} \mathrm{C}$ durante 24 horas. O material seco foi triturado e peneirado na granulometria entre $150 \mu \mathrm{m}<\mathrm{D}<250 \mu \mathrm{m}$.

Diluiu-se $0,80 \mathrm{~g}$ de $\mathrm{AM}$ em balões volumétricos de $2 \mathrm{~L}$ para obter a solução na concentração de $200 \mathrm{mg} \mathrm{L}^{-1}$. Uma curva de calibração foi construída no espectrofotômetro UV_VIS, marca Biospectro - modelo SP-22, no comprimento de onda de $664 \mathrm{~nm}$. Baseado no planejamento composto central, 3 variáveis foram analisadas em 5 níveis codificados, conforme a Tabela 1 .

Tabela 1 - Valores dos fatores atribuídos ao planejamento composto central

\begin{tabular}{cccc}
\hline Níveis codificados & $\begin{array}{c}\text { Concentração de } \\
\text { AM }\left(\mathrm{mg} \mathrm{L}^{-1}\right)\end{array}$ & $\mathrm{pH}$ & $\begin{array}{c}\text { Quantidade de CA } \\
\text { (g) em 100 mL de } \\
\text { solução }\end{array}$ \\
\hline$-\alpha$ & 50 & 5 & 0,2 \\
\hline-1 & 80 & 6 & 0,3 \\
\hline 0 & 125 & 7 & 0,4 \\
\hline+1 & 170 & 8 & 0,5 \\
\hline$+\alpha$ & 200 & 9 & 0,6 \\
\hline
\end{tabular}

Com o espectrofotômetro UV-visível, no comprimento de onda de $664 \mathrm{~nm}$, mediu-se a absorbância, convertida em concentração de azul de metileno através da curva de calibração, calculando a eficiência e a quantidade de corante adsorvida. Os ajustes dos dados de equilíbrio experimentais foram feitos através do modelo de isoterma de Langmuir.

\section{RESULTADOS E DISCUSSÕES}

O estado estacionário entre as fases líquida e sólida é apresentado na Figura 1 como exemplo. Notam-se que os espaços vazios do adsorvente ficam ligeiramente esgotados depois de 80 min, após isso a adsorção é aproximadamente constante. 


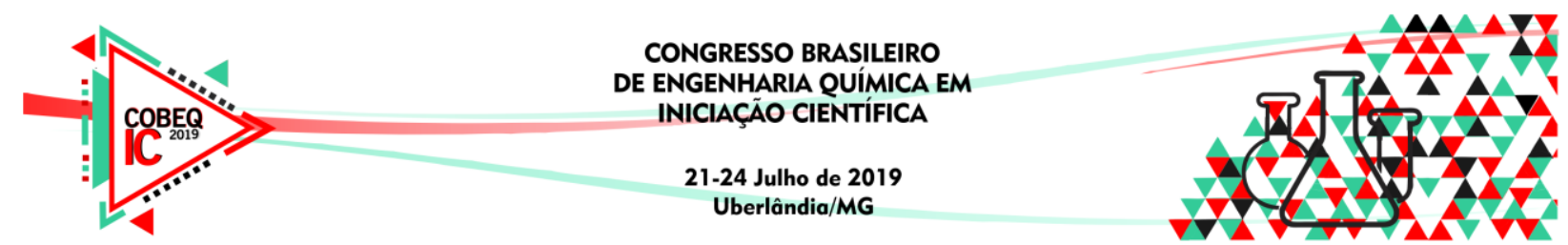

Figura 1 - Cinética de adsorção para experimentos de 1 a 9.

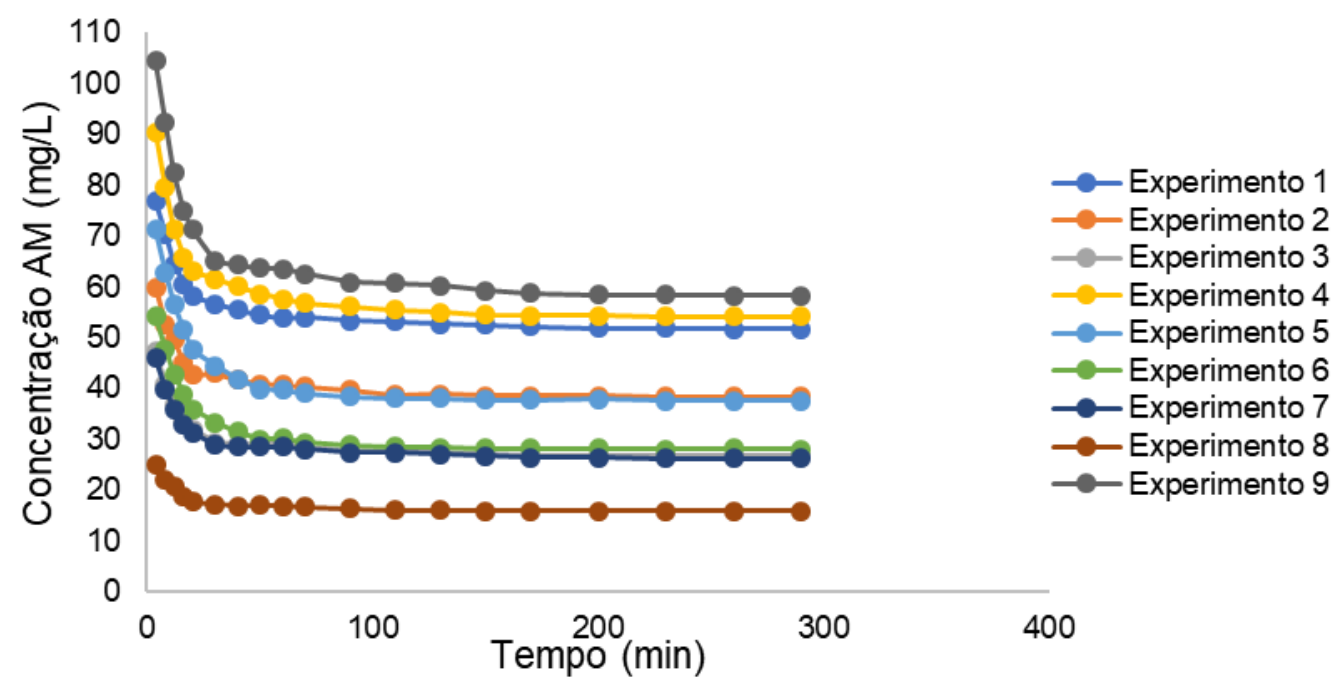

Em todos os experimentos constatou-se uma queda repentina da concentração de corante já nos primeiros 20 minutos de contato. Isso ocorreu porque, inicialmente, há uma grande quantidade de sítios de adsorção vazios, preenchidos pelas moléculas do corante com o passar do tempo. Os resultados mostraram que um período de 80 minutos já é suficiente, o que revela a casca de arroz como material eficiente na adsorção desse poluente. Para a visualização dos efeitos das variáveis na resposta utilizou-se o gráfico de Pareto, Figura 2.

Figura 2 - Gráfico de Pareto do processo de adsorção do AM na CA.

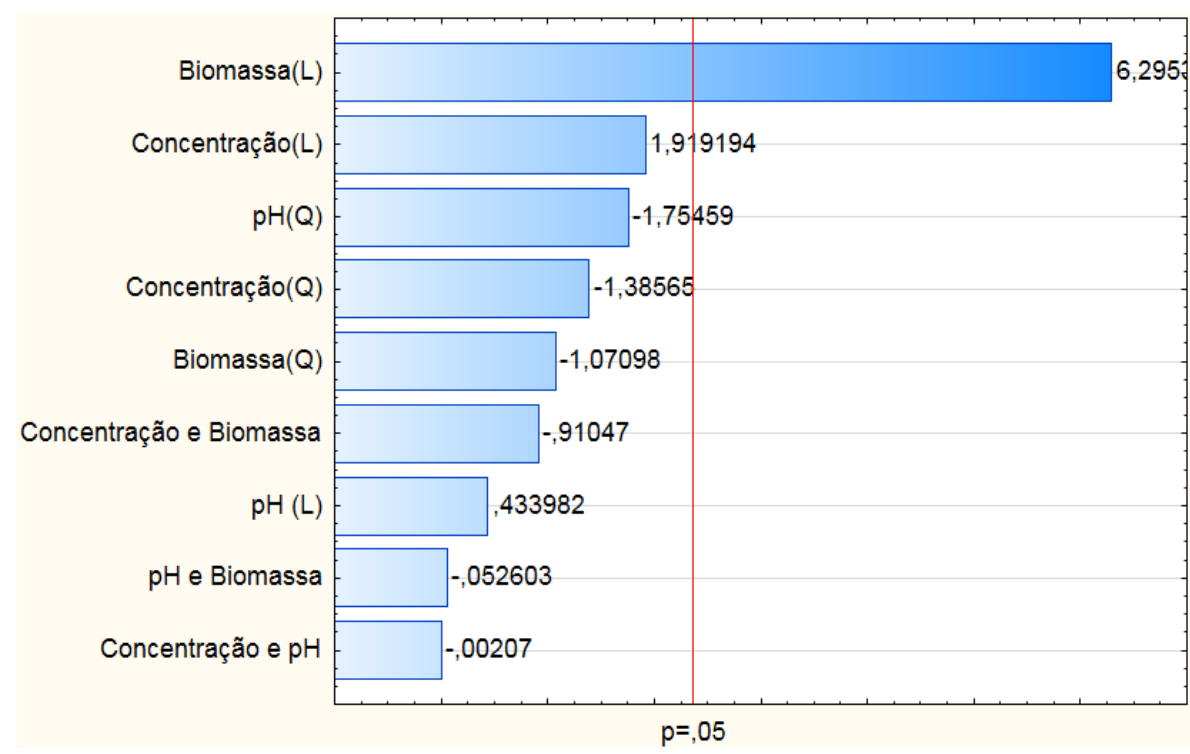

A variável biomassa, quando comparada às outras variáveis, possui uma maior influência no processo de adsorção, pois é nela que se encontram os sítios de adsorção e quanto maior a quantidade de biomassa mais eficiente é o processo. Embora as variáveis concentração e $\mathrm{pH}$ apresentem alguma influência, seus valores para os efeitos são nitidamente 


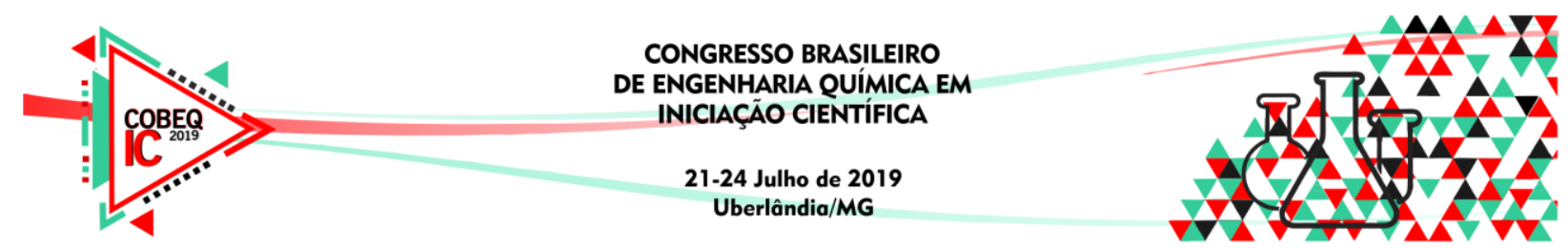

mais baixos. A Figura 3 apresenta a superfície de resposta relacionando a eficiência em função da biomassa e da concentração.

Figura 3 - Superfície de resposta em função da biomassa e concentração.



Nota-se que a melhor eficiência encontrada está localizada na maior concentração inicial de AM, associada com a maior quantidade de biomassa, sendo o percentual desse valor maior que 80. Após isso, fez-se uma análise da isoterma de equilíbrio para o experimento 16, escolhido por ter o melhor rendimento. A análise da Tabela 2 revela o modelo de Langmuir como mais adequado para a temperatura ambiente, visto que os valores das somas dos mínimos quadráticos $\left(\mathrm{Qui}^{2}\right)$ apresentou um melhor ajuste para os dados de adsorção de corante-casca de arroz nas condições estudadas.

Tabela 2 - Parâmetros para os modelos de Langmuir e Freundlich

\begin{tabular}{ccc|ccc}
\multicolumn{2}{c|}{ Langmuir } & Erro (+/-) & \multicolumn{2}{c}{ Freundlich } & Erro (+/-) \\
\hline qmax & 0,193 & 0,002 & $\mathrm{~m}$ & 0,369 & 0,012 \\
$\mathrm{~b}$ & 0,452 & 0,015 & $\mathrm{k}$ & 0,074 & 0,001 \\
$\mathrm{R}^{2}$ & 0,994 & & $\mathrm{R}^{2}$ & 0,986 & \\
$\mathrm{Qui}^{2}$ & 0,0000065 & Qui $^{2}$ & \multicolumn{2}{c}{0,0000153} \\
\hline
\end{tabular}

\section{CONCLUSÃO}

Este trabalho mostrou que a casca de arroz possui boa capacidade em adsorver o corante azul de metileno nas condições estudadas. A análise estatística aponta que a quantidade de biomassa é a variável mais significativa do processo. A condição ótima do processo foi atingida com eficiência de 79,4\%, na menor concentração de $\mathrm{AM}, \mathrm{pH}$ de 7 e na maior quantidade de biomassa. Dos modelos de isotermas testados, o que gerou uma confiabilidade maior foi o modelo de Langmuir. 


\section{REFERÊNCIAS}

CARVALHO, T., FUNGARO, D.A., IZIDORO, J.C., Adsorção do corante reativo laranja 16 de soluções aquosas por zeólita sintética. Química Nova, v.33, p. 358-363, 2010.

GOMIDE, R., Operações Unitárias: adsorção. São Paulo: Edição própria do autor, 1983.

McCABE, W. L., SMITH, J. C., HARRIOT, P., Unit Operations of Chemical Engineering. McGraw Hill International Ed., 6th ed., 2001.

OLIVEIRA, S. P., SILVA, W. L. L, VIANA, R. R., Evaluation of the capacity of adsorption of methylene blue die in aqueous solutions in natural kaolinite and intercalated with potassium acetate. Pós-Graduação em Geociências - UFMT, Cuiabá, 2013.

SILVA, A. C., CIUFFI, K. J., NASSAR, E. J., CALEFI. O. S., FARIA, E. H., Adsorção do corante azul de metileno em caulinita funcionalizada com $\beta$-alanina. $X$ Encontro Brasileiro sobre Adsorção. Guarujá-SP, abr. 2014. 